प\$ SXQUAR8 QVHHUWURV, 2021: 11(2), abril-junio ISSN: 2304-0335 DOI: https://doi.org/10.17162/au.v11i2.627

\title{
EDITORIAL
}

\section{¿Qué puedo esperar del futuro? ${ }^{1}$}

\section{What can I expect from the future?}

\author{
Fernando Aranda Fraga ${ }^{2}$ \\ Universidad Adventista del Plata, Argentina ${ }^{2}$ \\ Orcid ID: https://orcid.org/0000-0002-9324-7605²
}

Autoridades presentes, directivos, docentes, personal de apoyo y alumnos de la Universidad Adventista del Plata, padres y demás familiares de graduandos, y especialmente queridos graduandos de la actual promoción.

Hace poco más de un par de siglos, quien fuera el más relevante y revolucionario pensador de la edad moderna, Emanuel Kant, expresó mediante tres preguntas lo que para él condensaba el sentido de la vida humana: ¿qué debo hacer?, ¿qué puedo saber?, ¿qué me cabe esperar?, cuestiones fundamentales de la existencia que, según él, podían resumirse en una sola: ¿qué es el hombre? La ética, la epistemología y la religión son las disciplinas encargadas de responder esas tres primeras preguntas, en tanto que de la última se ocupa la antropología.

Les propongo situarnos en el marco de estas tres preguntas kantianas para analizar desde ese lugar lo que muy posiblemente han llegado a ser ustedes al cabo de su primera formación académica universitaria, mientras están en la antesala del mundo profesional. Para ello invertiré un tanto el orden de las preguntas de Kant, abordando primeramente el tema del conocimiento.

Sin lugar a dudas, durante estos años que has pasado en la Universidad has aprendido muchas cosas, y al mismo tiempo también serás consciente de que parte de esos conocimientos han de quedar obsoletos dentro de unos años. Esto es así, no porque hayas aprendido contenidos viejos, no te asustes,

\footnotetext{
${ }^{1}$ Discurso académico presentado por el autor en oportunidad de realizarse una reciente colación de grados de la Universidad Adventista del Plata, Argentina.

2E-mail: fernando.aranda@uap.edu.ar.
} 
seguramente están muy actualizados, sino simplemente porque el ritmo vertiginoso en que se mueve actualmente la ciencia, y la transformación del mundo como efecto de ésta, no tienen tregua y es siempre exponencialmente superior al periodo que le precede. Habrás escuchado, no pocas veces, que mientras vas pasando por la universidad, como dijera Ortega y Gasset, “es mucho más importante el camino que la posada". Esto es, importa más el aprendizaje de métodos y procedimientos con los cuales logres obtener tus conocimientos y sepas resolver problemas, pues ello te permitirá actualizarte permanentemente y desentenderte de ideas y conceptos que van perdiendo sentido y utilidad en la vida real. Pero esto, de ninguna manera significa que debamos evitar o rechazar los contenidos, no existe aprendizaje en el vacío, sino simplemente ser capaces de separarlos entre accesorios y fundamentales, transitorios, es decir, temporales, y perdurables, o hasta incluso eternos. Semejante incorporación de conceptos te capacita para darle sentido a tu vida, a tu profesión y a tu deambular por el mundo. Ahora bien, ¿hay ideas o conceptos que hoy puedas juzgar como fundamentales y perdurables en el tiempo? ¿Te habremos preparado en ésta, tu Universidad, para que, estando a minutos de egresar de ésta, hoy alcances a discernirlos con corrección y precisión, sin temor a equivocarte? Te propongo realizar un breve ejercicio con el fin de evaluarlos y revisarlos.

Como bien recordarás, puesto que te lo fuimos repitiendo durante todos estos años de tu estancia con nosotros, hay dos valores primordiales que apuntamos a desarrollar en nuestros alumnos: excelencia y servicio. Si optaste por hacer tuyos estos dos valores, entonces habremos logrado nuestra misión como institución: que obtengas una formación como persona sana, digna, y como profesional competente y éticamente responsable. Luego, seguramente habrás internalizado una jerarquía propia y autónoma de valores, en que los fuiste ordenando de un modo acorde con la formación que lograste y las experiencias de vida que fuiste adquiriendo. Pero volvamos al saber.

Durante estos años te mostramos que nuestros principios se encuentran en las Sagradas Escrituras y que ésta se constituye en el libro por excelencia, fuente de toda sabiduría, como así también de toda clave posible de interpretación de la historia, del pasado, del presente y del futuro. Allí leemos, sin lugar a equívocos ni cálculo de probabilidades, que Dios, en la persona de Cristo, su Hijo, fue el Creador del Universo y por lo tanto también de nuestro mundo; que todo lo creó a partir de la nada, por Su palabra. Que Dios es Uno y trino al mismo tiempo, que nos creó lisa y llanamente porque así lo quiso, por amor. Que nos hizo a Su imagen y semejanza en dos versiones diferentes y complementarias: varón y mujer, con la misión de poblar el mundo, reflejando Su imagen, ser felices y hacer lo mismo con nuestros semejantes. También quisimos mostrarte que en la naturaleza hay multitud de evidencias súper claras que corroboran el relato bíblico, y que aquellas ambiguiedades que encontramos en el mundo natural son producto de nuestra mente finita e imperfecta, y que a partir de la caída en el pecado de nuestros más remotos antepasados, hace unos seis mil años, es incapaz de 
conocer la realidad tal cual es, simplemente porque esa caída inicial corrompió y disminuyó sustancialmente nuestras capacidades.

Aquel primer acto posmoderno de los inicios de nuestra historia, ese deseo incompatible con nuestra naturaleza esencial de pretender querer ser como dioses, tal como le propuso Satanás encarnado en una bella Serpiente a la primera pareja, dio lugar a un segundo y definitivo acto de amor de parte de nuestro Creador eterno y todopoderoso. Dios tenía un plan alternativo y para ello dio a su Hijo Jesús para que limpiara todas las imperfecciones de la humanidad, hacia el pasado y el futuro, con la única condición de arrepentirnos y que confiemos en Él, mediante una respuesta que es siempre individual, por simplificar de alguna manera el proceso de conversión del creyente cristiano. Así fue como en clase aprendiste e incorporaste nuestra escatología cristiana o, para decirlo más fácil, el plan de Dios de salvación para la humanidad. Semejante plan tiene como finalidad reconvertirnos en seres perfectos, morando con Dios en una tierra renovada y purificada por Él, acontecimiento organizador de nuestras acciones e intenciones de vida, o que al menos debiera serlo.

Junto a esta interpretación de la historia, la cual nos define teleológicamente como universidad, también cabe saber algunas cosas más, sobre las cuales abordo una muy acotada muestra: Por ejemplo, que la investigación es aquella actividad mental y de construcción social que nos ayuda a explorar el mundo desconocido, y que su profundización en el campo que elegimos para nuestra formación es lo que nos brinda ese carácter de expertos que ansiamos lograr en nuestro desempeño profesional. Que como tal se debe a la sociedad, con la finalidad de mejorar las condiciones de vida de la gente. Para lograrlo, no olvides nunca ese sentido crítico que tus profesores te transmitieron en clase durante estos pocos años que pasaste con nosotros. Recuerda que el pensamiento masa, o único, no contribuye en nada a mejorar el mundo, simplemente lo conserva y estanca. Haz siempre un esfuerzo más por reflexionar sobre tu objeto de estudio, recorriendo mentalmente todos los puntos de vista que te resulte posible; ganarás en profundidad y precisión, a la vez que te permitirá librarte de las ataduras de los prejuicios y lugares comunes o impuestos por las modas. Recuerda que el sentido común es siempre el menos común de los sentidos. Procura mantener siempre tu libertad de conciencia, que es el mejor y más eficaz remedio contra la insatisfacción y la alienación humanas. Y junto a todo esto intenta desarrollar lo más armoniosa y proporcionalmente posible todas tus facultades, del modo más integral y completo, desarrollando tus talentos al máximo grado que puedas, no solo en tu propio beneficio sino también de los demás. Esto es lo que puedo saber, intentando responder la segunda pregunta kantiana. Por supuesto también mucho más, pero específicamente sobre esto conviene guardar memoria siempre.

Si el mundo y el ser humano, entonces, fueran así como intentamos describirlos, ¿qué debo hacer? Kant ensayó una respuesta que nosotros conocemos como la "regla de oro" (Mat. 7:12) "obra 
de tal manera que tu máxima de conducta sea capaz de elevarse a norma universal", o parafraseando la regla de oro: "haz con los demás lo mismo que te gustaría que hagan contigo". Pero todavía nos falta el contenido de la norma. Para semejante prescripción nos auxilia nuestra declaración de misión y nuestros objetivos como institución educativa: formar personas que busquen la excelencia, la justicia, la solidaridad y la verdad, tener una vida al servicio de los demás. Desarrollar un carácter cristiano equilibrado, basado en los principios escritos en la Palabra de Dios. Llevar una vida ordenada. Adoptar un estilo de vida sano y cuidar nuestra salud psicofísica, desarrollando equilibradamente todas nuestras capacidades. Poseer una profunda sensibilidad social y espiritual que favorezca la solidaridad y las buenas relaciones entre las personas, comunidades y naciones; trabajar con honestidad, eficiencia y calidad, reconociendo ante todo la dignidad del trabajo útil como medio de ganarse la vida y el sustento diario. Cuidar en forma responsable los recursos que nos fueron confiados, tanto humanos como materiales. Respetar las ideas de nuestros semejantes, lo cual no significa compartirlas, sino mantener nuestra natural independencia de pensamiento al tiempo que seamos capaces de respetar lo que piensan los demás. Junto a esto, adquirir capacidad y entrenamiento en la cooperación, el diálogo y el consenso, especialmente en lo que respecta a normativas temporales en las que no existe un "escrito está". Reconocer con claridad la diferencia entre lo que es un principio y lo que constituye una norma. Desarrollar al máximo posible la capacidad de persuasión y motivación, dejando a un lado mecanismos que rayan en la imposición, especialmente cuando ésta es irracional y autoritaria. Si esto es lo que deberíamos hacer, entonces, intentando responder las cuestiones de Kant, ¿qué puedo o me cabe esperar?

En el ámbito de lo temporal seguramente podrás esperar, ante todo, y para ello te capacitaste adecuadamente, ser un excelente y competente profesional. Ser feliz a través de tu trabajo y ser útil a la sociedad en que te toque vivir. Cambiar el mundo y mejorarlo, dentro de tus posibilidades, aunque menos sea en cuanto al pequeño ámbito en que te toque participar. Aplicar tus conocimientos y ser capaz de medir, en un mercado cada vez más difícil y competitivo, tus propias competencias adquiridas durante tu carrera universitaria. Seguir formándote en lo personal y lo profesional a fin de no perder el tren de lo que está vigente en tu profesión, en un mundo cada vez más tecnificado, globalizado y controlado, regido por leyes originadas en el natural egoísmo humano.

Pero en lo que permanece y perdura en el tiempo, o mejor dicho lo trasciende, ¿qué puedo esperar? El propio Kant, un pensador secular, aunque profundamente creyente, afirmó que la respuesta última radicaba exclusivamente en la relación del Creador con sus criaturas, Dios y el ser humano.

Seguramente la UAP te preparó de la mejor manera posible para que mediante el ejercicio de tus habilidades profesionales adquiridas te presentes al mundo como un orgulloso egresado de sus aulas, para que en la excelencia que manifiestes como persona y como profesional seas capaz de mostrar 
aquello que existe en el mundo invisible, pero que es sustento de todo lo visible y sobre lo cual ejercerás de aquí en más tu influencia. En definidas cuentas, para que en todo cuanto puedas hacer o decir, mostrar o ejemplificar, sanar o restablecer, administrar, comunicar, enseñar o programar, predicar, auditar, conducir o liderar, y todas aquellas acciones que de un modo u otro representan tu rol en el mundo y sobre las vidas humanas como profesional, permitas que las personas con las que te relaciones logren ver y verificar un sentido de eternidad detrás de todo lo que hagas. Solo si esto se produce es que nosotros, tus profesores y directivos de esta Universidad, en nuestro rol circunstancial de profesionales formadores de personas para este mundo y la eternidad, podremos afirmar con seguridad que aquel sagrado principio que nos guía como institución universitaria, y que afirma que "educar es redimir", sea más que un mero y simple slogan o expresión de deseos, y se convierta en un principio ordenador verificablemente cierto.

Queridos graduandos, solo me resta desearles: ¡felicidades e infinitas bendiciones!! 